\title{
Conceptualising state-market-family relationships in comparative research: a conceptual goodness view on defamilization
}

\author{
HANNAH ZAGEL* (D) AND HENNING LOHMANN**

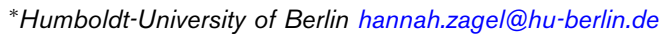 \\ **University of Hamburg henning.lohmann@uni-hamburg.de
}

\begin{abstract}
This study evaluates the strengths and weaknesses of defamilization as a concept for analysing state-market-family relationships in comparative perspective. A paradox has emerged around defamilization in the last decade; its use in empirical large- $\mathrm{N}$ research has grown markedly despite mounting criticism in theoretical discussions. Applying criteria of conceptual goodness, we find that the popularity of the concept is based on its high degree of parsimony, theoretical utility and field utility, but that there are problems with the resonance, coherence and differentiation of the concept. We argue that defamilization is most coherent and has greatest utility if the concept's roots in welfare state theory are fully acknowledged. In our view, this means that defamilization is best understood a) alongside the separate concept of familization, b) as a multidimensional concept in terms of economic and social dependencies in family relationships, and c) as a means of addressing both gender and intergenerational dependencies. Although suitable for operationalization in empirical research, the concept hence imposes high demands regarding the required data and possible analyses.
\end{abstract}

Keywords: Defamilization; family policy; comparative research; conceptual goodness; family dependencies

\section{Introduction}

The state-market-family nexus, which is at the heart of welfare state theories, has been conceptualized in many different ways. This is crucial, because sound concepts are needed to draw conclusions in comparative social policy analysis. Where the aim is to generalize to a large number of countries on issues such as how states reduce family dependencies, comparative concepts need to be relatively broad while still being sufficiently differentiated. Patterns of statemarket-family relationships across Europe have been analysed through the lens of male breadwinner/dual worker models (Lewis, 1992; Pascall and Lewis, 2004) or the concept of individualization in policy (Daly, 2011; Frericks et al., 2016). The concept of defamilization ${ }^{1}$ (originally Lister, 1994; McLaughlin and 
Glendinning, 1994) has been particularly widely applied in the last decade. It is increasingly being used in large- $\mathrm{N}$ comparisons that describe country variation in institutional settings or that aim to explain the outcomes of work-family policies.

Yet, this more widespread use of the concept in the empirical literature has, in our view, been accompanied by an increased uncertainty about the properties of defamilization and hence about what the empirical studies are comparing. The small but growing number of theoretical studies discussing defamilization have tended to take a critical stance towards it and to suggest alternative concepts. In this paper, we address a key question arising from this paradox of increasing popularity in empirical research despite overwhelming theoretical scepticism and ask: how good a concept is defamilization? Drawing on the literature on concept formation (Collier and Mahon, 1993; Gerring, 1999; Goertz, 2006; Sartori, 1991, 2009), we evaluate the conceptual goodness of defamilization, examine how the concept has been interpreted and applied, and propose a systematic approach to using it.

A review of the empirical literature featuring defamilization reveals the concept's popularity, but also indicates diverging interpretations. Defamilization is often used to conceptualize differences in how countries address intergenerational relationships (Dykstra, 2018; Saraceno and Keck, 2010) and support women's employment (Bambra, 2007; Chau et al., 2017; Cho, 2014; Foster et al., 2017; Zagel and Van Winkle, 2020). Increasingly, the concept is being used to study other outcomes as well, such as work intensity and happiness (de Hoon et al., 2016), material deprivation (Israel and Spannagel, 2018) and gender equality in long term care (Eggers et al., 2018). There is also a smaller but growing number of studies that discuss defamilization in theoretical terms. Renewed theoretical interest in the concept has particularly grown in the past decade. One reason for this is the concept's attractiveness; researchers have highlighted and praised it for the multiple perspectives on state-family relationships it combines (Kurowska, 2018; Leitner and Lessenich, 2007) and its multidimensionality (Hammer and Österle, 2003; Leitner and Lessenich, 2007; Lohmann and Zagel, 2016; Saraceno and Keck, 2010). Yet, others have criticized it for the same attributes and formulated new concepts so that defamilization is replaced (Saxonberg, 2013) or complemented (Kröger, 2011; Kurowska, 2018; Mathieu, 2016). ${ }^{2}$

Defamilization is closely related to other concepts in comparative family policy analysis such as familization, individualization, familialism and individualism and, like defamilization, there is no uniform understanding of these concepts either. Instead, the terms are frequently used to mean different things. For example, while familization is often assumed to be the opposite of defamilization, many authors have pointed out that it is in fact a complementary concept that refers to the degree of state support for care within the family (Leitner, 2003; 
Lohmann and Zagel, 2016; Eggers et al., 2018). The concept of individualization shifts the focus from family relationships to individuals and asks how much the state supports individual independence (Daly, 2011). By contrast, in the concept of familialism, the welfare state regime is the conceptual unit and not the country. Familialism supposes a perspective of categorical rather than gradual differences between countries as members of types or regimes (Leitner, 2003; Saraceno, 1994). Different ideas about familialism exist in academic and public discussions, but here, familialism concerns differences in how welfare states rely on the family as a welfare provider. Variations in familialism can be conceptualized as outcomes of different degrees of defamilization and familization.

In this paper, we take the paradox of the increased use of defamilization in large- $\mathrm{N}$ empirical studies despite growing theoretical criticism as a starting point for investigating its consistency and clarity as a concept. This is necessary, because when defamilization is not used arbitrarily it can serve as a valuable concept for understanding how welfare states shape state-family and familymarket relations. From the wider literature on concepts in comparative research, we chose Gerring's (1999) approach to evaluate conceptual goodness, because it acknowledges that concept formation is not simply about the application of strict rules and highlights the notion of trade-offs between different criteria. The approach provides a comprehensive list of criteria of conceptual goodness, allows for meticulous scrutiny and can reveal flaws and ambiguities in concepts. For defamilization, a concept that has grown in popularity despite not being extensively assessed when first proposed, such scrutiny is needed and promises to improve its conceptual consistency and clarity. We consider all the criteria but only examine the most pertinent ones to the case of defamilization in the in-depth discussion. We proceed in three steps. First, we briefly introduce all of Gerring's eight criteria of conceptual goodness and give a compact overview of how defamilization performs as a concept by revisiting its roots. Second, we zoom in on the criteria that are arguably most contentious for defamilization in three separate subsections: resonance, coherence and differentiation. Here, we further trace the concept's application in the empirical and theoretical literature. Finally, we summarize our insights by proposing a definition of defamilization that overcomes some of the identified problems. We conclude by discussing avenues for future research.

\section{The conceptual goodness of defamilization Criteria of conceptual goodness}

Any meaningful comparison presupposes sound concepts, because they define what is compared. An unclear concept makes it difficult to draw any comparative conclusions at all (Clasen, 2013). When research concerns empirical phenomena, its results depend crucially on terms and definitions (Gerring, 
1999; Sartori, 1991). Within theoretical debates in a given discipline, conceptual clarity is paramount for advancing the field. An ill-defined concept may be used arbitrarily, and misconceptions are likely to emerge in theoretical discussions (Podsakoff et al., 2016). Further, a lack of clarity can prompt confusion as to the purpose of the empirical study in question; likewise, it can create measurement problems and impede a meaningful interpretation of the results (Collier and Gerring, 2009).

The literature on concept formation builds on the observation that a lack of conceptual clarity is ubiquitous in the social sciences and identifies the need for systematic frameworks to assess existing concepts and form new ones. There are several prominent concept formation frameworks that are relatively strict and rely on fixed sets of rules. Gerring (1999) has proposed a different approach, which is based on the idea that concepts are always the result of trade-offs between different alternatives. The framework is systematic but refrains from formulating static rules. It consists of eight criteria of conceptual goodness, which can be used to evaluate and appraise concepts: familiarity, resonance, parsimony, coherence, differentiation, depth, theoretical utility and field utility. In this framework, assessing and formulating concepts means mediating between these eight criteria rather than applying them as rules (Gerring, 1999: 368). While all of the criteria describe a good concept, some are more central than others. Previous discussions in the concept formation and comparative social policy literatures suggest that coherence and differentiation are key quality criteria for concepts and are thus more important than, for example, familiarity and utility, which are somewhat subjective criteria. Our in-depth analysis in the following section focuses on the criteria with the most apparent conceptual trade-offs in relation to defamilization, which also include coherence and differentiation. We will consider the weighting of the criteria in our evaluation.

\section{How good a concept is defamilization?}

When assessing the concept of defamilization, it is important to note that it was introduced and defined in two different publications in the same year by different authors (Lister, 1994; McLaughlin and Glendinning, 1994). Although the respective authors chose slightly different terms, in both cases the concept was introduced with the same aim in mind: to add a gendersensitive concept to the comparative welfare state literature that could complement the key concept of decommodification, which centred on the male worker. Lister (1994: 37) defined 'defamilialisation' as 'the degree to which individual adults can uphold a socially acceptable standard of living, independently of family relationships, either through paid work or through the social security system'. McLaughlin and Glendinning stated that '[D]e-familization is constituted by those provisions and practices which vary the extent to which wellbeing is dependent on "our" relation to the (patriarchal) family' (1994: 65). The 
following appraisal of defamilization in light of Gerring's (1999) criteria will show that this dual concept formation was consequential for the concept's clarity and consistency. We will also address the semantic differences.

Turning to the first of Gerring's (1999) criteria, familiarity requires the concept in question to be consistent with established meanings of the described phenomenon; its definition has to incorporate features that are commonly subsumed in the concept and the term should align with common sense language. When defamilization emerged in 1994, it was a neologism and thus by definition unfamiliar. Nevertheless, it combined two theoretical references that had a high degree of familiarity. First, it referred to one of the most popular concepts of comparative welfare state research at the time, decommodification (Esping-Andersen, 1990); and second, it included the family, one of the three components of the prominent 'welfare triangle' (state, market, family). Both of its definitions likewise drew on familiar vocabulary in the (comparative) mainstream and gendered welfare state research of the time. The concept was intended to describe how paid work (in the market) or the social security system (the state) would enable a 'socially acceptable standard of living' (Lister) or 'wellbeing' (McLaughlin and Glendinning) independent of the (patriarchal) family.

The second criterion, resonance, requires a concept to 'click' with the reader, to 'sound right' in the context in which it is used. On this criterion, defamilization has arguably performed less well. Several commentators have expressed irritation at the combination of the negatively loaded prefix 'de-' with the word family. Does defamilization mean that the state should reduce family bonds? And more generally, is there a normative implication of defamilization? The concept arguably reflects a trade-off between familiarity and resonance, which will be addressed in the discussion below.

The third criterion, the degree of parsimony, which refers to a term's length and its definition, is sufficiently high in the case of defamilization. Its definition is succinctly summarized as 'the degree of support of individuals' independence from family relationships' (Lohmann and Zagel, 2016: 49).

The fourth criterion, coherence, concerns the internal consistency of the concept's characteristics and attributes. Gerring (1999) argues that this can be considered the most important criterion, because it distinguishes a good concept from a term that describes a coincidental clustering of phenomena. Arguably, because defamilization is a multidimensional concept and refers to various categories of policy beneficiaries, the attributes subsumed under it may be arbitrarily selected. Does defamilization describe state support for reducing both women's dependence on male breadwinners and children's dependence on their parents? And what is the logical connection between the reduction of these different types of dependencies? Defamilization has recently been criticized for its lack of coherence, and researchers have debated whether the concept 
should be complemented or replaced (Kröger, 2011; Kurowska, 2018; Mathieu, 2016; Saxonberg, 2013). There is an arguable trade-off between the concept's coherence and its depth in representing the range of state-family relationships. This will also be discussed in more detail in Section 3.

The fifth criterion, differentiation, means that a concept should be clearly bounded and distinguishable from other related concepts and should be operationalizable. Defamilization only partially fulfils this, because the concept overlaps with others which evolved in the gendered welfare state literature around the same time, most notably the concepts of the capacity to form and maintain a household (Orloff, 1993), personal autonomy (O'Connor, 1993) and the male breadwinner model (Lewis, 1992). In addition, when it comes to the newer concepts that are meant to replace (Saxonberg, 2013) or complement (Kröger, 2011; Kurowska, 2018; Mathieu, 2016) defamilization, the dividing lines are not clear. All of the concepts refer to differences in how states regulate the gendered dependencies between couples or within families but all emphasize different aspects of this definition. Considering these boundary issues and acknowledging that 'differentiation is a problem' (Gerring, 1999: 379), we discuss the differentiation of defamilization in more detail below.

According to Gerring (1999), a concept acquires, depth, the sixth criterion, by subsuming a range of shared characteristics underneath it. As indicated above, the concept of defamilization is a good example of how this criterion may conflict with some of the other criteria, such as coherence and differentiation. Overall, defamilization is relatively deep, as it covers a broad range of state policies towards the family and pertains to a longstanding discussion of the development of welfare states.

The seventh criterion, theoretical utility, reflects the need for concepts to be useful for specialist discussions of phenomena in a given discipline. Concepts are the building blocks of theories and classify the phenomena of interest to provide a cluster of categories that map the universe under study. Defamilization fulfils the criterion of theoretical utility. Rooted in welfare state theory, it is a key concept for conceptualizing the relationships between market, state and family. It is applicable to a wide range of different sociological and political science research questions in comparative welfare state research.

Field utility, the eighth criterion, is also emphasized by Sartori (2009) and requires the concept to take its own position without unsettling the field by overlapping with other concepts. Defamilization fulfils this criterion by filling the conceptual space around the relationship between the state and the family in the field. As shown by its widespread application in empirical studies, defamilization arguably provides better field utility than similar concepts such as the capacity to form and maintain a household (Orloff, 1993) and personal autonomy (O'Connor, 1993), which are less linked to family relationships. Furthermore, the evolution of the discourse around the term - which went from 
being almost exclusively used within the feminist literature to a more general use - shows its impact within the comparative welfare state literature.

\section{Three challenges to the conceptual goodness of defamilization}

Building on the idea of mediating between the eight criteria of conceptual goodness underlying Gerrings's framework, this section discusses defamilization in light of the three criteria with notable trade-offs: resonance, coherence and differentiation.

\section{Resonance: defamilization does not sound right}

There are two problems with defamilization in terms of the criterion of resonance, both related to the semantics of the term. First, the two initial definitions of the concept built on different root terms: 'familial' and 'family'. Second, defamilization combines the negatively loaded prefix $d e$ - with the positively connoted term family, which prompts cognitive irritation. The use of the prefix is a reference to the popular concept of decommodification. Hence, defamilization's unfortunate construction with a negative prefix can be seen as a trade-off with the familiarity criterion.

\section{Root terms}

On the first problem of resonance, the different root terms of defamilization, the literature has been surprisingly silent. Although some note the different ways of writing (Leitner and Lessenich, 2007: 244), most authors use the terms interchangeably, going as far as to adjust the term to fit their own preferred way of writing (e.g. Leitner, 2003; Lohmann and Zagel, 2016; Saraceno and Keck, 2010; Saxonberg, 2013). ${ }^{3}$ This practice warrants comment, and not just because it raises concerns about citation customs. We will consider whether the different terms convey different meanings and whether either of the two terms resonates more clearly with the attributes it should possess.

The present paper cannot hope to undertake a linguistic analysis of the root terms family and familial with a view to uncovering their diverging meanings, nor to inquire into the initial considerations of the authors of the two concepts. Both undertakings go beyond what we can achieve and may also overstate the intentions of the scholars who first introduced the concepts. Instead, our evaluation is based on a review of the uses of the different terms in subsequent research. A search of academic literature databases shows that defamilization and defamilialization are used interchangeably with no discernible difference in the attributes to which they refer. When examining studies using either of the terms, we noted that they typically investigate the degrees to which states reduce family dependencies. Although Lister's (1994) definition of defamilialization originally focused on economic dependencies, and it was 
this that Esping-Andersen (1999) picked up on, we equally find studies focusing on care relationships using defamilialization as a term (Eggers et al., 2018; Leitner, 2003). Thus, the different terms used do not translate into substantial differences in meaning but rather seem to reflect preferences and path dependencies in wording.

\section{The negative prefix}

Regarding the second resonance-related problem, some have wondered whether the combination of the negative prefix 'de-' with the term family implies that state policies should somehow 'reduce' family. This notion is almost as old as the term itself. As Sainsbury (1996: 75) noted: 'The term "defamilialization" has two unfortunate consequences. As a parallel to decommodification it perpetuates a clumsy vocabulary. More importantly, the term conjures up associations of weakening or abolishing the family; but what is at stake is remaking the patterns of family relationships and bestowing social rights upon family members'. Despite her objections, Sainsbury uses the term and concept throughout her book; others have followed. The term was fully incorporated into social science terminology when Esping-Andersen (1999) made 'defamilialization' a cornerstone of his typology of welfare regimes - despite assessing it as 'yet another admittedly awkward word' (p. 45). Two decades on, replacing an established concept seems neither feasible nor advisable.

There is no question about McLaughlin and Glendinning's (1994) original intentions when formulating the term, as they explicitly stated that defamilization 'is not about whether or not people live in something recognizable as a family, or whether people have enduring emotional and material relationships with other "family" members', but about 'the terms and conditions under which people engage in families' (McLaughlin and Glendinning, 1994: 65). Likewise, Saraceno (1997) emphasizes that defamilization 'does not imply a breaking of family bonds' (p.94). Esping-Andersen (1999), too, asserts that defamilization 'does not imply "anti-family"; on the contrary it refers to the degree to which households' welfare and caring responsibilities are relaxed' (Esping-Andersen, 1999: 51). With its focus on 'independence from the family', defamilization parallels decommodification in focusing on 'independence from the market'. In both concepts, independence is understood in gradual rather than categorical terms and the reference point is total dependence rather than total independence. Just as decommodification does not describe how states abolish the market but conceptualizes the degree to which states enable individuals to be relatively independent of the market, defamilization describes state support for relative independence from the family. Consequently, authors like Leitner (2003) have put familialism - i.e. a type of society where families are the key providers of welfare - in the centre of the debate on defamilization. In this view, 
all societies are familialistic, but they differ gradually in how much independence from the family they provide.

The 'anti-family' reading of defamilization not only refers to its analytical substance but also suggests a normative interpretation of the concept. In particular, feminist scholarship using the concept of defamilization is thought to imply that there is something desirable in abolishing the family as an institution. Of course, feminism is not a singular, coherent perspective in social theoretical thinking. Indeed, from a feminist perspective, which aims to unravel power relationships in the nuclear family and empower women, state support for reducing family dependencies would be desirable. On the other hand, the economic individualization of women has been widely criticized in feminist research (Lewis and Giullari, 2005; Ostner, 2010). Extensive defamilization could hence also be seen critically with a feminist lens on the grounds that it replaces family dependencies with state dependencies or dependence on the market. Moreover, as indicated above, defamilization is about more than economic dependencies in heterosexual couple relationships. For example, defamilization also describes state support to reduce both adult children's duty to care for their elderly parents and parents' obligations to provide financially for their adult children (Saraceno and Keck, 2010). The concept hence does not seem to readily serve any one political agenda. Rather, the concept was introduced as a theoretical instrument that can be used to understand the complex statemarket-family relationships that feminist research unpacked.

\section{Coherence: Who is defamilized and in what respect?}

There is a trade-off between coherence and conceptual depth in the case of defamilization. Although its meaning as 'state support to reduce family dependencies' may seem intuitive, defamilization combines numerous facets that 'generate several senses' (Gerring, 1999: 374). The concept comprises state provision of policies to reduce gender and intergenerational dependencies in economic and social relationships. Its multidimensionality - it includes policies that support economic independence and reduce social or care dependencies - requires careful consideration. And this is complicated, because the concept also addresses dependencies between different types of family members: parents and children, mothers and fathers, and grandparents and grandchildren.

Research using the concept of defamilization has mainly focused on mothers' economic independence from a male breadwinner, which is arguably inseparable from their children's dependence on them for care. Defamilization is used to describe policies that reduce women's economic dependence by supporting their participation in the labour market. To operationalize defamilization, empirical studies have used indicators of parental leave policies (Bambra, 2007; de Hoon et al., 2016; Leitner, 2003; Lohmann and Zagel, 2016) and of childcare policies (Chau et al., 2017; Cho, 2014; de Hoon et al., 2016; Israel 
and Spannagel, 2018; Leitner, 2003; Lohmann and Zagel, 2016). Childcare policies likewise address care relationships, but this is a rare focus in the empirical literature (for discussions of this gap see Kröger, 2011; Mathieu, 2016).

Defamilization of social or care dependencies has been further conceptualized in terms of older parents' relationships with their adult children (Kurowska, 2018; Saraceno and Keck, 2010). Care provision to older people relieves adult children of their care responsibilities and supports their parents in maintaining independence. To measure defamilization in terms of intergenerational dependencies, studies have used indicators of state support for elder care (Cho, 2014; Leitner, 2003; Lohmann and Zagel, 2016; Saraceno and Keck, 2010). Defamilization in terms of intergenerational care dependencies particularly requires researchers to consider care-giver and care-receiver perspectives (Leitner and Lessenich, 2007).

As shown by this short review, defamilization's coherence as a concept may diminish when its different facets are spelled out. Scholars' focus on one of the subdimensions (social/economic) or on one of the types of relationships (gender/intergenerational) may highlight differences rather than similarities. Arguably, conceptual coherence is more problematic when we follow the definition provided by McLaughlin and Glendinning (1994) compared to Lister's (1994) version. This is because Lister explicitly defines defamilization in terms of the economic dependencies of women on men and leaves the care aspect aside. Nevertheless, scholars have criticized the concept of defamilization for its lack of coherence. While few have suggested getting rid of the concept altogether (Saxonberg, 2013), some have considered adding specifications to differentiate the different dimensions of defamilization, such as social defamilization (Leitner and Lessenich, 2007) or care defamilization (Michoń, 2015). Others have proposed limiting defamilization to Lister's definition (economic dependencies in gender relationships) or complementing it with other concepts that cover the care dimension (Kröger, 2011; Mathieu, 2016).

There is a further issue: namely, how defamilization is achieved - exclusively through state support or via market processes? In our view, this is not a major source of incoherence, because, particularly in the more recent literature, authors have implicitly or explicitly interpreted defamilization as being about state support or state mediation (see Kurowska, 2018: 46; Lohmann and Zagel, 2016: 52; Saraceno and Keck, 2010: 677). However, most notably, Esping-Andersen has indicated that 'De-familialization through Markets' (1999: 63ff.) is an alternative. The main question he addresses in this respect is how the tax-benefit system affects opportunity costs and the cost of childcare. We interpret this less as a question of 'state vs. market' but rather as 'welfare through the tax system vs. welfare through cash benefits and in-kind provisions'. Both types of measures can be regarded as defamilization when it is defined as state support to reduce family dependencies. 


\section{Differentiation: drawing boundaries}

Another reason why the conceptual goodness of defamilization may be limited is because it overlaps with other concepts and hence lacks differentiation. If the definitions of alternative concepts clearly described phenomena other than defamilization, then we could describe defamilization as a differentiated concept. Defamilization, as a medium range concept, overlaps with concepts at a higher and a lower level. Daly's (2011: 7) preference for the wider, more general concept of individualization over defamilization is justified by the idea that a higher degree of defamilization means treating people as individuals rather than as family members. Treating people as individuals is a core element of individualization. However, without any further mention of the family, individualization does not refer solely to independence from the family (Beck-Gernsheim, 2002) but describes a more general feature of modern societies (Beck, 1986).

Defamilization likewise lacks differentiation from narrower concepts when these overlap with subdimensions of defamilization. Some scholars have proposed new concepts as complements to defamilization, like dedomestication (Kröger, 2011) or demotherization (Mathieu, 2016). These terms have been coined in response to defamilization. Any overlaps and differences are explicitly laid out. This is less the case with the concept of degenderization (Saxonberg, 2013). It starts off from the misleading notion that defamilization primarily aims 'to eliminate gender roles' (p. 32). From this viewpoint, it is difficult to see where the two concepts overlap, particularly as the concept of degenderization shares attributes of the economic and gender subdimensions of defamilization while ignoring others.

Other concepts have evolved in parallel to defamilization within the feminist literature (Zagel and Lohmann, forthcoming). This work has criticized Esping-Andersen's (1990) focus on male paid work and decommodification as one of the main characteristics of welfare states. For example, the concept of the capacity to form and maintain one's own household (Orloff, 1993), which is similar to economic defamilization, describes state support for economic independence; the same applies to the concept of personal autonomy (O'Connor, 1993). In favour of the defamilization concept, it may be argued that these two overlapping concepts focus less on family relationships. In particular, the concept of personal autonomy is much broader than defamilization as it includes autonomy over other life domains, such as reproductive or bodily autonomy (O'Connor, 1993). The male breadwinner model concept, defined by Lewis (1992), which also clearly describes gendered economic dependencies, likewise overlaps with defamilization, but this is conceived as a household-level concept.

Looking at the empirical comparative literature on state support for families that has emerged since the relevant concepts were introduced in the early, 1990s, defamilization is more frequently applied than the concepts by Orloff and 
O'Connor. This could be due to defamilization's aptness for operationalization as a quantitative indicator. Furthermore, despite the problems discussed above, the term 'defamilization' is highly recognizable, it resonates and it refers clearly to the family. For example, it is unclear how family policy alone could achieve wider personal autonomy beyond merely reducing family dependencies. The widely used male breadwinner model concept shares less overlap with defamilization due to its emphasis on the couple level.

A differentiation problem is also evident when it comes to the relationship between defamilization and familization. As mentioned in the introduction, familization was initially perceived as the opposite of defamilization. In more recent years, it has come to be understood as a complementary concept describing the degree to which states support care performed by family members and hence foster a model with high family dependencies (Leitner, 2003; Lohmann and Zagel, 2016; Eggers et al., 2018). In contrast, familialism is often used to denote types of welfare states that are characterized by a specific combination of attributes on defined subdimensions. Leitner (2003) has distinguished between the following four care regimes, which feature a specific combination of high or low familization and defamilization: explicit familialism, implicit famililialism, optional familialism and de-familialism. In other cases, it has not always been clear how the subdimensions relate to defamilization. An example of this are Saraceno's and Keck's (2010) three intergenerational policy regimes: familialism by default, supported familialism and de-familization. EspingAndersen's (1999) use of familialism and defamilialization is inconsistent. To some extent, he interprets both terms as opposites on a continuum, but apparently also regards familialism as a type. Drawing on studies by Saraceno and Keck (2010) and Leitner (2003), Lohmann and Zagel (2016) have suggested viewing defamilization and familization as the (measurable) policy dimensions and familialism/individualism as ideal-typical country-level aggregate outcomes.

\section{(Re-)defining defamilization}

The previous sections demonstrated that defamilization is a successful concept in terms of its application and reception in the literature, but that it also has some severe problems that have generated discontent with and misunderstandings of the concept. In this section, we identify features that define defamilization as a central concept for analyzing the state-market-family nexus; we opt not to add another definition of the concept or to propose a new one to replace it.

\section{Defamilization and familization: two aspects of the state-market-family nexus}

First, we suggest following the initial definitions. We define defamilization as the degree of support for individuals' independence from family relationships, 
where family relationships entail gender and intergenerational relations characterized by imbalances in the distribution of social and economic resources and thereby create dependencies. Hence, defamilization describes one particular aspect of state-family relations. Focusing on this aspect not only increases the coherence of the concept but also allows for clearer differentiation from other concepts. As mentioned above, the boundaries of the concepts that have evolved from the literature on defamilization are not always clear cut. In our view, defamilization works best in tandem with a concept of familization, which describes the degree to which states increase social and economic dependencies between family members (based on Leitner, 2003). As such, defamilization and familization should be understood as two separate concepts, which pertain to different welfare state attributes. Policy measures that relate to both concepts may be implemented in various combinations across welfare states. For example, a country with a high degree of defamilization, reflected in good access to affordable childcare provision, good access to institutional care for older people and short, well-paid parental leave, may at the same time have high familization in that it provides generous child benefits and child tax credits; by contrast, another country with a similar level of defamilization might only provide very limited family allowances.

\section{Multidimensionality}

In line with previous interpretations, we think it is important to emphasize that defamilization is a multidimensional concept. For instance, Leitner and Lessenich (2007: 252f.) have argued convincingly against adopting a narrow perspective that focuses solely on care-givers or on the commodification of (female) labour. But multidimensionality only results in more coherent concepts if the subdimensions are laid out clearly. We followed Leitner and Lessenich's proposal and analytically distinguished between reducing social and economic dependencies. Conceptualized this way, defamilization allows for the analysis of a wide range of complex social and economic relationships. Social and economic dependencies are strongly interrelated with family relationships, and these are difficult to disentangle empirically. Therefore, it seems more sensible to address both within the concept of defamilization than to propose separate concepts for each subdimension. For example, children depend socially and economically on their parents as long as they do not earn their own income. Ideas about the 'generational contract' imply that the dependency relationship shifts when adult children have their own income and their parents transition into retirement. Empirically, however, a net downward flow from older parents to their adult children has commonly been noted (Albertini et al., 2007). Spouses are economically dependent on each other, with their respective incomes strengthening the autonomy of each. Social 
dependence between spouses can also be an issue, if one spouse requires care due to sickness or old age.

Where the state provides policies that relieve dependence on one of the dimensions, dependencies in the other dimension may shift or remain unchanged (Leitner and Lessenich, 2007). For example, access to affordable childcare can relieve parents' care dependencies and support their ability to participate in paid work and reduce economic dependencies. Using the two concepts of familization and defamilization, researchers can conceptualize and empirically map different degrees of state intervention on the two dimensions of social and economic dependencies within and between countries.

\section{Gender and intergenerational relationships}

As previously noted, defamilization is deeply rooted in feminist theorizing and is hence commonly seen as relating to the degree to which the state reduces gender dependencies. In other words, the emphasis has often been on policies that support the independence of women from men. This gender-focused perspective, which tends to be normatively charged, still bears on the concept, although the term defamilization does not necessarily imply it. If we take the definition of 'support of individuals' independence from family relationships' seriously, however, the concept must include intergenerational relationships and samesex couple relationships too (Saraceno and Keck, 2010). As mentioned above, these relationships encompass parents-child relationships, as well as grandparent-grandchild ones. Explicitly acknowledging the different forms of relationships and intended beneficiaries of policies adds to the coherence of the underlying general concept. In this line of argument, Leitner and Lessenich (2007) have emphasized the rarely discussed perspectives of the care-giver and of the care-receiver that is inherent to the concept. They argue that the care-giver perspective is reductionist and stress that, from a policy point of view, the perspectives can be conflicting. While this is an important point to note in the context of conceptualizing care relationships, it is less central for describing the degree of support for reducing dependencies between care-giver and care-receiver.

Rather than requiring each study using defamilization to be about all of the relationships, researchers should be clear about the limits of the particular approach adopted (see e.g. Daly, 2020 on the lack of a child-perspective), while acknowledging that defamilization is about more than supporting women's employment. The abstract notion of 'state support to reduce family dependencies' may then be operationalized with a focus on selected family relationships. Table 1 provides examples of various defamilizing policies categorized by dependency dimension and type of relationship. The list is incomplete and serves to illustrate the different kinds of policy measures. For example, pension credits granted for periods when individuals (mostly women) interrupted their 
TABLE 1. Policies reducing social and economic dependencies in gender and intergenerational relationships

\begin{tabular}{|c|c|c|c|}
\hline & & \multicolumn{2}{|l|}{ Relationships } \\
\hline & & Gender & Intergenerational \\
\hline \multirow[t]{2}{*}{ Dependence } & Economic & $\begin{array}{l}\text { - Pension credits for care time } \\
\text { - Parental leave (for fathers) }\end{array}$ & - Education stipends \\
\hline & Social & - Institutional or home care services & - Childcare services \\
\hline
\end{tabular}

employment to take care of children or other related persons reduce the caring person's dependence on their spouse. Education stipends, on the other hand, reduce economic dependencies between parents and their children. Social dependencies between spouses decline when they have access to care services for sick or older people, and social dependencies between parents and children diminish when parents can avail of childcare services.

\section{Summary and outlook}

Defamilization is an increasingly popular concept in comparative research on state-market-family relationships and it has been widely used in empirical and theoretical studies since its formation over twenty-five years ago (Lister, 1994; McLaughlin and Glendinning, 1994). Many scholars have seen great merit in the concept when describing differences in state support to relieve family dependencies across countries. Others have raised concerns about the concept's clarity and proposed new or complementary concepts. Using Gerring's (1999) criteria of conceptual goodness, we revisited the strengths and the weaknesses of defamilization.

The analysis showed that the concept is a highly parsimonious term, whose association with established meanings invokes familiarity among scholars in the research field. When it was coined, defamilization filled a theoretical gap in the comparative welfare state literature, which had lacked a concept to complement decommodification (Esping-Andersen, 1990) as this was developed with the male worker in mind. Both theoretical utility and field utility are high, as the concept addresses theoretical arguments from existing theorizing and contributes a new angle. The relationships between state, market and the family are neatly addressed by defamilization, and it enables more accurate descriptions of country differences by including gender and intergenerational relationships.

The assessment has shown that studies describing differences in the degree of defamilization have meant different things, and that the unsystematic use of the concept has hampered its further elaboration. We argued that its theoretical and field utility are greatest if its roots in welfare state theory are fully acknowledged. In our view, this means that the concept should be a) understood 
separately from or in tandem with the concept of familization, b) defined and conceptualized in multidimensional terms as relating to state support to reduce economic and social dependencies between family members, and c) acknowledged as addressing both gender and intergenerational dependencies.

The conclusions of our review of defamilization based on the criteria of conceptual goodness have several implications for future empirical research. First, and most generally, careful concept specification is an essential component of any comparative study. The dispute around the term 'defamilization' is a case where the lack of scrutiny has led to discontent and controversy among researchers. While discussions about conflicting ideas concerning a concept may help to sharpen definitions, such discussions can be unproductive if misunderstandings dominate. In recent years, a number of valuable works have aimed to overcome ambiguities in the early definitions of defamilization. Further research should build on these rather than perpetuating old misunderstandings. Second, if defamilization is understood as a multidimensional concept - covering the interlinked aspects of social and economic independence as well as gender and intergenerational relationships - researchers need to clearly state which of these subdimensions they focus on. Third, an operationalization of the concept is still impeded by a lack of data. If there is no other option but to use weak measures of defamilization and its subdimensions, any deficiencies should be carefully explained. At the same time, efforts should be undertaken to increase the availability of valid and reliable data, as is the case for other concepts. We suggest highlighting the particular shortcomings rather than obfuscating them. Only with such openness will we be able to overcome limitations in data availability for certain indicators, countries or time periods.

\section{Notes}

1 The terms defamilization and defamilialization were introduced synchronically. The differences in terminology will be discussed below. In this article, we have opted to use the shorter term 'defamilization' throughout the article unless we were discussing the differences or citing a source using the other term. We proceed in the same manner with related terms such as familism or familization (instead of familialism or familialization).

2 A search in the Web of Science publication database supports the view that defamilization has proliferated in recent years. For the last five years (2016-2020) we found 55 articles with defamilization or spelling variants of this term in the title, the abstract or as keyword, 52 with breadwinner model and far fewer with earner model, earner-carer model or degenderization. A comparison with occurrences of decommodification helps to put these numbers into perspective. Not surprisingly there are more articles with reference to decommodification, but only about double as many ( 98 articles). During the period 1990 to 2015 , we found 59 mentions of defamilization, 116 entries referring to breadwinner models and 182 mentions of decommodification.

3 We also follow this approach in this article in order to increase readability. See introduction. 


\section{References}

Albertini, M., Kohli, M. and Vogel, C. (2007), 'Intergenerational transfers of time and money in European families: common patterns - different regimes?', Journal of European Social Policy, 17 (4), 319-34.

Bambra, C. (2007), 'Defamilisation and welfare state regimes: a cluster analysis', International Journal of Social Welfare, 16 (4), 326-38.

Beck, U. (1986), Risikogesellschaft: Auf dem Weg in eine andere Moderne, Frankfurt am Main: Suhrkamp.

Beck-Gernsheim, E. (2002), Reinventing the Family: In Search of New Lifestyles, Malden Mass.: Polity Press.

Chau, R., Yu, S., Foster, L. and Lau, M. (2017), 'Defamilisation measures and women's labour force participation - a comparative study of twelve countries', Journal of International and Comparative Social Policy, 33 (1), 73-86.

Cho, E. Y.-N. (2014), 'Defamilization typology re-examined: Re-measuring the economic independence of women in welfare states', Journal of European Social Policy, 24 (5), 442-54.

Clasen, J. (2013), 'Defining comparative social policy', in A Handbook of Comparative Social Policy, Second Edition, Edward Elgar Publishing, accessed 14 April 2020 at https://www. elgaronline.com/view/edcoll/9781849803663/9781849803663.00012.xml.

Collier, D. and Gerring, J. (eds.) (2009), Concepts and Method in Social Science: The Tradition of Giovanni Sartori, London: Routledge.

Collier, D. and Mahon, J. E. (1993), 'Conceptual “Stretching” Revisited: Adapting Categories in Comparative Analysis', The American Political Science Review, 87 (4), 845-55.

Daly, M. (2011), 'What Adult Worker Model? A Critical Look at Recent Social Policy Reform in Europe from a Gender and Family Perspective', Social Politics: International Studies in Gender, State \& Society, 18 (1), 1-23.

Daly, M. (2020), 'Children and their Rights and Entitlements in EU Welfare States', Journal of Social Policy, 1-18.

de Hoon, S., Lam, J. and Keizer, R. (2016), 'Examining the Relation between Part-Time Work and Happiness in Dual-Earner Couples from a Life Course Perspective: Incorporating Individual, Couple and Country Characteristics', LCC Working Paper, The University of Queensland.

Dykstra, P. A. (2018), 'Cross-national Differences in Intergenerational Family Relations: The Influence of Public Policy Arrangements', Innovation in Aging, 2 (1), accessed at https:// doi.org/10.1093/geroni/igxo32.

Eggers, T., Grages, C., Pfau-Effinger, B. and Och, R. (2018), 'Re-conceptualising the relationship between de-familialisation and familialisation and the implications for gender equality - the case of long-term care policies for older people', Ageing \& Society, 1-27.

Esping-Andersen, G. (1990), The Three Worlds of Welfare Capitalism, Princeton N.J.: Princeton University Press.

Esping-Andersen, G. (1999), Social Foundations of Postindustrial Economies, Oxford; New York: Oxford University Press.

Foster, L., Chau, R. and Yu, S. (2017), 'The impact of defamilisation measures on gender and pensions: a comparison between the UK and seven other European countries', Journal of Poverty and Social Justice, 25 (3), accessed at https://doi.org/10.1332/ 175982717 X14999284090397.

Frericks, P., Höppner, J. and Och, R. (2016), 'Institutional Individualisation? The Family in European Social Security Institutions', Journal of Social Policy, 45 (4), 747-64.

Gerring, J. (1999), 'What Makes a Concept Good? A Criterial Framework for Understanding Concept Formation in the Social Sciences', Polity, 31 (3), 357-93.

Goertz, G. (2006), Social Science Concepts: A User's Guide, Princeton: Princeton University Press.

Hammer, E. and Österle, A. (2003), 'Welfare State Policy and Informal Long-Term Care Giving in Austria: Old Gender Divisions and New Stratification Processes Among Women', Journal of Social Policy, 32 (1), 37-53. 
Israel, S. and Spannagel, D. (2018), 'Material deprivation in the EU: A multi-level analysis on the influence of decommodification and defamilisation policies', Acta Sociologica, 62 (2), $152-73$.

Kröger, T. (2011), 'Defamilisation, Dedomestication and Care Policy: Comparing Childcare Service Provisions of Welfare States', International Journal of Sociology and Social Policy, 31 (7/8), 424-40.

Kurowska, A. (2018), '(De)familialization and (De)genderization - Competing or Complementary Perspectives in Comparative Policy Analysis?', Social Policy \& Administration, 52 (1), 29-49.

Leitner, S. (2003), 'Varieties of Familialism: The Caring Function of the Family in Comparative Perspective', European Societies, 5 (4), 353-75.

Leitner, S. and Lessenich, S. (2007), '(In-)dependence As Dependent Variable: Conceptualizing and Measuring "De-familization"', in J. Clasen and N. Siegel (eds), Investigating Welfare State Change: The 'dependent Variable Problem' in Comparative Analysis, Cheltenham UK; Northampton MA: Edward Elgar, pp. 244-60.

Lewis, J. (1992), 'Gender and the Development of Welfare Regimes', Journal of European Social Policy, 2 (3), 159-73.

Lewis, J. and Giullari, S. (2005), 'The adult worker model family, gender equality and care: the search for new policy principles and the possibilities and problems of a capabilities approach', Economy and Society, 34 (1), 76-104.

Lister, R. (1994), “She Has Other Duties": Women, Citizenship and Social Security', in S. Baldwin and J. Falkingham (eds), Social Security and Social Change: New Challenges to the Beveridge Model, New York; London: Harvester Wheatsheaf, pp. 31-44.

Lohmann, H. and Zagel, H. (2016), 'Family policy in comparative perspective: The concepts and measurement of familization and defamilization', Journal of European Social Policy, $26(1), 48-65$.

Mathieu, S. (2016), 'From the Defamilialization to the "Demotherization" of Care Work', Social Politics: International Studies in Gender, State \& Society, 23 (4), 576-91.

McLaughlin, E. and Glendinning, C. (1994), 'Paying for Care in Europe: Is There A Feminist Approach?', in L. Hantrais and S. Mangen (eds), Family Policy and the Welfare of Women, vol. 3, Loughborough, pp. 52-69.

Michon', P. (2015), 'Waiting for the incentives to work: comparative analysis of the parental leave policies in the Visegrad countries', Community, Work \& Family, 18 (2), 182-97.

O'Connor, J. S. (1993), 'Gender, Class and Citizenship in the Comparative Analysis of Welfare State Regimes: Theoretical and Methodological Issues', The British Journal of Sociology, 44 (3), 501-18.

Orloff, A. (1993), 'Gender and the Social Rights of Citizenship: The Comparative Analysis of State Policies and Gender Relations', American Sociological Review, 58 (3), 501-18.

Ostner, I. (2010), 'Farewell to the Family As We Know It: Family Policy Change in Germany', German Policy Studies, 6 (1), 211-44.

Pascall, G. and Lewis, J. (2004), 'Emerging Gender Regimes and Policies for Gender Equality in a Wider Europe', Journal of Social Policy, 33 (3), 373-94.

Podsakoff, P. M., MacKenzie, S. B. and Podsakoff, N. P. (2016), 'Recommendations for Creating Better Concept Definitions in the Organizational, Behavioral, and Social Sciences', Organizational Research Methods, 19 (2), 159-203.

Sainsbury, D. (1996), Gender, Equality, and Welfare States, Cambridge [England]; New York NY: Cambridge University Press.

Saraceno, C. (1994), 'The Ambivalent Familism of the Italian Welfare State', Social Politics: International Studies in Gender, State \& Society, 1 (1), 60-82.

Saraceno, C. (1997), 'Family Change, Family Policies and the Restructuring of Welfare', in Family, Market and Community, Paris: OECD Publishing, pp. 81-10o.

Saraceno, C. and Keck, W. (2010), 'Can We Identify Intergenerational Policy Regimes in Europe?', European Societies, 12 (5), 675-96.

Sartori, G. (1991), 'Comparing and Miscomparing', Journal of Theoretical Politics, 3 (3), 243-57. 
Sartori, G. (2009), 'Guidelines for concept analysis', in D. Collier and J. Gerring (eds), Concepts and Method in Social Science: The Tradition of Giovanni Sartori, London: Routledge.

Saxonberg, S. (2013), 'From Defamilialization to Degenderization: Toward a New Welfare Typology', Social Policy \& Administration, 47 (1), 26-49.

Zagel, H. and Lohmann, H. (forthcoming), Conceptual approaches in comparative family policy research', in R. Nieuwenhuis and W. van Lancker (eds), Handbook on Family Policy, Basingstoke: Palgrave.

Zagel, H. and Van Winkle, Z. (2020), 'Women's Family and Employment Life Courses Across Twentieth-Century Europe: The Role of Policies and Norms', Social Politics: International Studies in Gender, State \& Society, accessed at https://doi.org/10.1093/ sp/jxzo56. 